\title{
Psychological Distress in Morbid Obesity in Relation to Weight History
}

\author{
Maria Letizia Petroni, MD'; Nicola Villanova, MD²; Sebastiano Avagnina, \\ $\mathrm{MD}^{3}$; Maria Antonia Fusco, $\mathrm{MD}^{4}$; Giuseppe Fatati, $\mathrm{MD}^{5}$; Angelo Compare, \\ PhD, PsyD ${ }^{6}$; Giulio Marchesini, MD²; and the QUOVADIS Study Group*
}

\begin{abstract}
${ }^{1}$ Nutrition Rehabilitation Unit and ${ }^{6}$ Clinical Psychology Laboratory, IRCCS Istituto Auxologico Italiano, Piancavallo (Verbania); ${ }^{2}$ Department of Internal Medicine and Gastroenterology, "Alma Mater Studiorum” University of Bologna, Bologna; ${ }^{3}$ Division of Dietetics and Clinical Nutrition, S. Giovanni Battista Hospital, Turin; ${ }^{4}$ Division of Dietetics and Clinical Nutrition, San CamilloForlanini Hospital, Rome; ${ }^{5}$ Division of Dietetics and Diabetology, Santa Maria Hospital, Terni, Italy

*A complete list of participants in the QUOVADIS study has been previously published in Diabetes Nutr Metab 2003; 16: 115-24.
\end{abstract}

Background: Very few data are available on psychological distress in morbidly obese subjects in relation to the history of their weight. In subjects with childhood obesity, psychological distress might be better than in adult-onset obesity, because of progressive adaptation to the social stigma.

Methods: Psychological distress was tested in relation to BMI at age 20 years (BMI-20), weight history and somatic co-morbidities in 632 treatment-seeking, morbidly obese participants from the QUOVADIS cohort (130 men, 502 women; mean age 45.5 years). The number of dieting attempts/year, BMI increase and cumulative BMI loss since age 20 were calculated as weight cycling parameters. The Symptom Check List-90 (SCL-90), the Psychological General WellBeing (PGWB), the Binge-Eating Scale, and the ORWELL-97 questionnaire were used to score psychometry and health-related quality of life (HRQL). Complications were quantitatively assessed by a modified Charlson's score.

Results: BMI-20 was normal in $35 \%$ of cases and $>35$ $\mathrm{kg} / \mathrm{m}^{2}$ in only $14 \%$. Psychometric scores were not different in relation to BMI-20, when corrected for age, with the exception of the General Health scale of PGWB, showing a greater distress in subjects with normal BMI-20. In most cases, the prevalence of pathological results of questionnaires showed a $\mathrm{J}$ shaped curve, with participants with normal BMI-20 or

Correspondence to: Prof. Giulio Marchesini, Department of Internal Medicine and Gastroenterology, "Alma Mater Studiorum" University of Bologna, 9, via Massarenti, 40138, Bologna, Italy. Fax: +39-051-6364502; e-mail: giulio.marchesini@unibo.it those with Class II-III obesity in early adulthood having the highest prevalence of psychological/psychiatric distress and poor HRQL. Weight cycling was a risk factor for binge-eating, depression and interpersonal sensitivity in SCL-90, whereas somatic co-morbidities adversely affected most SCL-90 and all PGWB scales.

Conclusion: Weight cycling and somatic co-morbidities, but not age of onset of obesity, are the main factors negatively influencing psychological health in treatment-seeking, morbidly obese subjects.

Key words: Morbid obesity, quality of life, complications, weight cycling, psychometry

\section{Introduction}

Obesity is a complex disease where somatic and psychological/psychiatric factors contribute to severe distress and poor health-related quality of life (HRQL). The burden of somatic co-morbidities is generally associated with the severity and duration of obesity; psychological distress may be both the cause and effect of obesity, generated by the social stigma of obesity and contributing to the low self-esteem, which is a leading cause of treatment failure. ${ }^{1}$

Subjects with Class III obesity (Body mass index - BMI $\geq 40 \mathrm{~kg} / \mathrm{m}^{2}$ ) are a category particularly prone to co-morbidities. Cross-sectional studies have 
shown that class III obesity is characterized by a high prevalence of features of the metabolic syndrome, ${ }^{2}$ including cardiovascular complications, by osteoarticular and respiratory diseases, and by high rates of psychiatric/psychological distress. ${ }^{3}$ Also disorders in eating behavior are common, ${ }^{4}$ and weight cycling contributes to progressive weight gain. ${ }^{5}$ Finally, their HRQL and psychological wellbeing may be extremely poor. ${ }^{6-8}$

The weight history of adult subjects with morbid obesity who seek treatment at medical centers, may be extremely variable. Adult obesity may be the consequence of childhood obesity, but in most cases weight gain is observed from early adulthood, either progressive or with recurrent weight-cycling episodes. Thus, when entering a weight-reducing program, either medical or surgical, ${ }^{9}$ the psychiatric/psychological profile of the patient may thus be extremely altered, ${ }^{10}$ but variable, and two scenarios may be hypothesized: 1) participants with childhood obesity might have progressively adapted to the social stigma, thus limiting the psychological burden of disease in adulthood; 2) in the same patients, weight cycling associated with longstanding obesity and the related somatic co-morbidities might have further increased the psychological distress and HRQL, rendering these patients extremely difficult to treat.

The QUOVADIS study is a large cross-sectional analysis of obese patients seeking treatment at medical Italian centers. ${ }^{3}$ Its large database provides a unique opportunity to test the differences in psychiatric and psychological distress in morbidly obese patients in relation to their BMI in early adulthood (age 20 years), to their weight history and to the presence of somatic comorbidities.

\section{Materials and Methods}

\section{Patients}

The philosophy of the QUOVADIS study and the general characteristics of the population have been partly published in a previous report. ${ }^{3}$ Briefly, all participants entering the study were interviewed as to their weight history, previous somatic and mental diseases, hospital admission during the previous year, self-evaluation of physical activity and eating pattern, and completed a set of self-administered questionnaires. We report an analysis based on 632 participants (130 men and 502 women) with morbid obesity (BMI $\geq 40 \mathrm{~kg} / \mathrm{m}^{2}$ ) whose complete data were available. Their characteristics are reported in Table 1. Their mean age and BMI at entry did not differ according to gender.

The weight history was checked according to a pre-defined structured interview including questions about body weight at the age of 20 years (BMI at the age of 20 years $-B M I-20$ ), age of first dieting and the number of times patients had lost weight as a result of dietary programs, as previously reported. ${ }^{5}$ All weight data were transformed into BMI units to facilitate comparison between genders. The values reported by systematic interviews were used to compute the total number of dieting programs and total BMI loss because of dieting programs. The number of dieting attempts was normalized for age difference since first dieting; all other parameters of diet history were normalized for age difference since the age of 20 years. The following parameters of weight cycling were then identified: number of dieting attempts/year, BMI change since age 20 and cumulative BMI loss, both expressed in $\mathrm{kg} / \mathrm{m}^{2} /$ year. $^{5}$ The cut-offs corresponding to the 75th percentile of each of these three parameters in the whole QUOVADIS population were selected to identify patients with a weight history more indicative of weight cycling. ${ }^{5}$ A weight cycling score (WCS) (from 0 to 3 ) was therefore assigned to each patient, according to the number of weight cycling parameters above the cut-off value of the 75 th percentile. No attempt was made to characterize the weight history before the age of 20 years.

To facilitate handling of data, all measured or reported items had been implemented in an extranet database provided by CINECA (Casalecchio di Reno, Italy), an Interuniversity Consortium of 15 Italian Universities, using the AMR (Advanced Multicenter Research) methodology, which allows the management of the whole research using standard web-browsers.

All participants signed an informed consent to take part in the study, which was approved by the ethics committees of the individual centers, after approval by the committee of the coordinating center (University of Bologna). 
Table 1. Demographic and weight history characteristics of the study population, in relation to BMI at the age 20 years; numbers are expressed as mean \pm SD or as prevalence

\begin{tabular}{|c|c|c|c|c|c|c|}
\hline & $\begin{array}{l}\text { All cases } \\
(n=632)\end{array}$ & $\begin{array}{l}\text { BMI <25 } \\
(n=221)\end{array}$ & $\begin{array}{c}\text { BMI 25-30 } \\
(n=198)\end{array}$ & $\begin{array}{c}\text { BMI 30-35 } \\
(n=126)\end{array}$ & $\begin{array}{l}\text { BMI >35 } \\
(n=87)\end{array}$ & $P^{*}$ \\
\hline Male (\%) & 21 & 13 & 23 & 25 & 26 & 0.006 \\
\hline Age (years) & $45.5 \pm 5.3$ & $48.7 \pm 9.0$ & $44.0 \pm 9.7$ & $41.1 \pm 11.9$ & $35.3 \pm 10.9$ & $<0.001$ \\
\hline Education & & & & & & 0.006 \\
\hline $\begin{array}{l}\text { Primary/ Secondary/ Comr } \\
\text { or vocational/ Degree (\%) }\end{array}$ & $\begin{array}{l}\text { nmercial } \\
21 / 38 / 36 / 5\end{array}$ & $28 / 31 / 38 / 3$ & $20 / 35 / 39 / 6$ & $17 / 38 / 36 / 9$ & $11 / 45 / 42 / 2$ & \\
\hline $\begin{array}{l}\text { Civil status } \\
\text { Single, divorced/ Married, } \\
\text { co-habiting/Widoved (\%) }\end{array}$ & $24 / 71 / 5$ & $16 / 78 / 6$ & $23 / 72 / 5$ & $28 / 68 / 4$ & $43 / 56 / 1$ & $<0.001$ \\
\hline $\begin{array}{l}\text { Employment status } \\
\text { Student/Self-employed/Em } \\
\text { Housewife/Unemployed/ }\end{array}$ & nployee/ & & & & & $<0.001$ \\
\hline Retired/ (\%) & $3 / 14 / 36 / 30 / 5 / 11$ & $1 / 9 / 33 / 38 / 3 / 16$ & $1 / 19 / 35 / 29 / 5 / 11$ & 2/14/43/25/8/8 & $16 / 16 / 35 / 20 / 8 / 4$ & \\
\hline BMl at entry $\left(\mathrm{kg} / \mathrm{m}^{2}\right)$ & $45.5 \pm 5.3$ & $44.5 \pm 4.5$ & $45.4 \pm 4.7$ & $45.8 \pm 5.2$ & $47.9 \pm 7.3$ & $<0.001$ \\
\hline $\begin{array}{l}\text { BMl at age } 20\left(\mathrm{~kg} / \mathrm{m}^{2}\right) \\
\text { BMl gain from }\end{array}$ & $28.3 \pm 6.1$ & $22.5 \pm 1.8$ & $27.2 \pm 1.5$ & $32.1 \pm 1.4$ & $39.8 \pm 4.0$ & $<0.001$ \\
\hline age $20\left(\mathrm{~kg} / \mathrm{m}^{2}\right)$ & $17.2 \pm 7.2$ & $22.0 \pm 5.0$ & $18.1 \pm 4.9$ & $13.7 \pm 5.3$ & $8.0 \pm 7.4$ & $<0.001$ \\
\hline $\begin{array}{l}\text { Cumulative BMI loss since } \\
\text { age } 20\left(\mathrm{~kg} / \mathrm{m}^{2} / \text { year }\right)\end{array}$ & $1.00 \pm 1.11$ & $0.70 \pm 0.66$ & $1.00 \pm 1.13$ & $1.17 \pm 1.36$ & $1.59 \pm 1.34$ & $<0.001$ \\
\hline Age at first dieting (years) & $25.4 \pm 10.4$ & $30.0 \pm 10.2$ & $25.5 \pm 9.2$ & $22.8 \pm 9.4$ & $18.0 \pm 8.8$ & $<0.001$ \\
\hline No. of dietary attempts/year & $0.45 \pm 0.45$ & $0.37 \pm 0.32$ & $0.45 \pm 0.47$ & $0.51 \pm 0.52$ & $0.54 \pm 0.54$ & 0.214 \\
\hline Somatic disease score & $1.58 \pm 1.20$ & $1.77 \pm 1.19$ & $1.55 \pm 1.12$ & $1.65 \pm 1.28$ & $1.12 \pm 1.14$ & $<0.001$ \\
\hline
\end{tabular}

*Kruskall-Wallis or Chi-square test

\section{Methods}

\section{Questionnaires}

The Symptom Check List-90 questionnaire was used to identify participants with a psychopathological distress. ${ }^{11}$ For each item, the patients score how much that problem has distressed them during the last week, with responses ranging from 0 (not at all) to 4 (extremely). The 90 items of the test are summarized into 9 domains (somatization, obsessivecompulsive thoughts, interpersonal sensitivity, depression, anxiety, hostility, phobic anxiety, paranoid conceiving, psychotic behavior), and into a general symptom index (GSI), which is used as an indicator of the overall psychological distress. ${ }^{12} \mathrm{~A}$ value $\geq 1$ in GSI or in any specific subscale is suggestive of psychopathology (1.00 - 1.49, mild; 1.50 - 1.99, moderate; $\geq 2.00$, severe).
The Psychological General Well-Being (PGWB) questionnaire was used to score psychological distress. ${ }^{13}$ The responses to 22 questions are arranged in 6 affective states: anxiety, depressed mood, positive well-being, self-control, general health and vitality. The Italian version of the questionnaire has been recently validated, and normative values are available to compare the results with population standards. ${ }^{14}$

The Binge Eating Scale was used to detect binge eating, ${ }^{15}$ and values $\geq 17$ were considered suspect of binging, whereas values $\geq 27$ were considered highly predictive of a binge eating disorder.

Finally, The Obesity-Related Well-being 97 (ORWELL-97) questionnaire was used to determine the impact of obesity on health-related quality of life (HRQL). The questionnaire was specifically developed to score the intensity and the subjective relevance of physical and psychological distress generated by overweight. ${ }^{16}$ 


\section{Scores}

Weight history was scored according to previouslypublished, 75th percentile cut-offs. ${ }^{5}$ Three items were considered: 1) recurrent dieting (cut-off, number of dieting attempts $>0.56 /$ year); 2) BMI gain since age 20 years (cut-off, $0.706 \mathrm{~kg} / \mathrm{m}^{2} /$ year); 3) cumulative BMI loss (cut-off, $0.964 \mathrm{~kg} / \mathrm{m}^{2} /$ year).

The presence of somatic diseases was used to calculate a composite score, according to Charlson et $\mathrm{al},{ }^{17}$ with modifications. For this purpose, one point was added for the reported presence of any of the following states: diabetes, hypertension, other endocrine disorders, liver or biliary disease, hip or knee pain. The presence of cardiovascular disease (any condition, including angina, previous myocardial infarction or stroke, peripheral or carotid vascular disease) and a previous diagnosis of neoplasia were given 2 points.

\section{Statistical Analysis}

Initially, differences between groups were tested for statistical significance using unpaired $t$-test or Kruskall-Wallis test, due to non-gaussian distribution of data, as appropriate. Differences in the prevalence of categorical data were tested by $\mathrm{R} \times \mathrm{C} \mathrm{Chi}{ }^{2}$-test.

Logistic regression analysis was performed using dichotomized scores of GSI and individual domains of the SCL-90 as dependent variables. The cut-off value was set at 1.0 for all scales, but a sensitivity analysis using the cut-offs of 1.5 was also performed, and the results were qualitatively confirmed (not reported in detail). Values in the total score and in the individual domains of PGWB were transformed into Z-scores (difference between patient value and control mean, divided by control standard deviation), using age and gender matched values of a general Italian population. ${ }^{14} \mathrm{Z}$-scores $\leq 1.0$ were considered the cut-offs of psychological distress. The prevalence of pathological BES values was tested at the two different cut-offs of $\geq 17$ and $\geq 27$. The ORWELL-97 was dichotomized considering a score $\geq 70$, corresponding to the 75 th percentile of the population, as indicative of a clinically significant burden of obesity on HRQL. Independent variables were BMI-20, the clinical score of somatic diseases and the three individual components of weight history. All analyses were adjusted for age, gender and BMI at presentation.
Data in the text and in the Tables were presented as means $\pm \mathrm{SD}$ or as prevalence. $P$ values $<0.05$ were considered statistically significant.

\section{Results}

At time of enrolment, $35 \%$ of cases reported a BMI20 in the normal range; in only $14 \%$ of cases, BMI was $>35 \mathrm{~kg} / \mathrm{m}^{2}$ in early adulthood, reflecting childhood obesity. The prevalence of male gender was lower in participants who were normal weight at age 20 years, and there was a progressive trend towards younger age at time of enrolment with increasing BMI at age 20 (Table 1). Participants who were already obese at young age were more frequently students, in keeping with their younger age. They were also characterized by higher educational levels, and were more frequently single or divorced. Their BMI at time of enrolment was moderately higher, but BMI increase from age 20 was much lower.

Age at first attempt to lose weight was only 18 years in participants with Class II or III obesity at 20 years, and 30 years in those with normal body weight. The weight history was remarkably different among groups. The average number of dieting attempts was not different when related to the timespan from early adulthood, but the cumulative weight loss per year increased with the obesity grade at age 20 years. By contrast, the presence of somatic diseases was more common in participants who were normal weight at age 20 , but the difference was no longer present after adjustment for differences in age (ANOVA, $P=0.143$ ).

The scores of BES, SCL-90, PGWB and ORWELL-97 were not different in relation to BMI at age 20 (Table 2), with the notable exception of the Somatization scale of SCL-90 and the General Health scale of PGWB, which showed a more severe distress in those who were normal weight at age 20. These data were confirmed by correlation analysis. BMI-20 was negatively correlated with the Somatization scale ( $\mathrm{r}=0.118 ; P=0.003)$, and positively with the General Health domain $(r=0.117$; $P=0.003$ ). Also in this case, the association of BMI20 with the Somatization scale was no longer significant after adjustment for age (ANOVA, $P=0.612$ ), whereas the association was maintained 
Table 2. Scores of the Binge Eating Scale, Symptom CheckList-90 and ORWELL 97, according to BMI at the age 20 years $($ mean $\pm S D)$

\begin{tabular}{|c|c|c|c|c|c|}
\hline & $\begin{array}{l}\text { BMI-20, <25 } \\
(\mathrm{n}=221)\end{array}$ & $\begin{array}{l}\text { BMI-20, 25-30 } \\
\quad(n=198)\end{array}$ & $\begin{array}{c}\text { BMI-20, 30-35 } \\
\quad(n=126)\end{array}$ & $\begin{array}{c}\text { BMI-20, >35 } \\
(\mathrm{n}=87)\end{array}$ & $P^{*}$ \\
\hline Binge Eating Scale & $15.7 \pm 9.1$ & $15.6 \pm 9.4$ & $16.1 \pm 8.5$ & $16.9 \pm 10.2$ & 0.704 \\
\hline \multicolumn{6}{|l|}{ Symptom CheckList-90 } \\
\hline General Symptom Index & $0.91 \pm 0.57$ & $0.88 \pm 0.64$ & $0.89 \pm 59.6$ & $0.89 \pm 0.70$ & 0.556 \\
\hline Somatization & $1.35 \pm 0.51$ & $1.16 \pm 0.53$ & $1.16 \pm 0.63$ & $1.10 \pm 0.84$ & 0.006 \\
\hline Obsessive-compulsive thoughts & $0.95 \pm 0.49$ & $0.90 \pm 0.52$ & $0.94 \pm 0.65$ & $0.89 \pm 0.92$ & 0.516 \\
\hline Interpersonal sensitivity & $0.89 \pm 0.50$ & $0.96 \pm 0.60$ & $1.03 \pm 0.76$ & $1.08 \pm 0.10$ & 0.549 \\
\hline Depression & $1.05 \pm 0.05$ & $1.01 \pm 0.81$ & $1.00 \pm 0.76$ & $1.04 \pm 0.90$ & 0.495 \\
\hline Anxiety & $0.92 \pm 0.69$ & $0.87 \pm 0.72$ & $0.82 \pm 0.70$ & $0.84 \pm 0.74$ & 0.345 \\
\hline Hostility & $0.70 \pm 0.66$ & $0.71 \pm 0.71$ & $0.79 \pm 0.77$ & $0.77 \pm 0.73$ & 0.727 \\
\hline Phobic anxiety & $0.47 \pm 0.61$ & $0.46 \pm 0.64$ & $0.41 \pm 0.57$ & $0.51 \pm 0.70$ & 0.659 \\
\hline Paranoid conceiving & $0.92 \pm 0.74$ & $0.90 \pm 0.76$ & $1.01 \pm 0.76$ & $0.89 \pm 0.69$ & 0.487 \\
\hline Psychotic behavior & $0.52 \pm 0.53$ & $0.56 \pm 0.64$ & $0.53 \pm 0.57$ & $0.61 \pm 0.71$ & 0.297 \\
\hline \multicolumn{6}{|l|}{ Psychological General Well-Being } \\
\hline Total score & $63.6 \pm 18.1$ & $65.8 \pm 20.4$ & $66.2 \pm 18.6$ & $66.3 \pm 20.8$ & 0.344 \\
\hline Depressed mood & $10.8 \pm 3.0$ & $11.1 \pm 3.2$ & $11.1 \pm 3.1$ & $11.0 \pm 3.3$ & 0.331 \\
\hline Anxiety & $14.7 \pm 4.9$ & $15.0 \pm 5.6$ & $15.3 \pm 5.1$ & $14.8 \pm 5.5$ & 0.604 \\
\hline Positive well-being & $9.3 \pm 3.8$ & $9.9 \pm 4.3$ & $9.6 \pm 3.7$ & $10.0 \pm 4.1$ & 0.334 \\
\hline Self-control & $10.1 \pm 3.4$ & $10.3 \pm 3.3$ & $10.4 \pm 3.5$ & $10.6 \pm 3.6$ & 0.490 \\
\hline General health & $8.5 \pm 2.7$ & $9.1 \pm 3.0$ & $8.9 \pm 3.0$ & $9.3 \pm 3.2$ & 0.042 \\
\hline Vitality & $10.2 \pm 3.7$ & $10.4 \pm 4.3$ & $10.7 \pm 4.0$ & $10.7 \pm 4.3$ & 0.526 \\
\hline ORWELL-97 & $60.5 \pm 30.2$ & $57.4 \pm 29.4$ & $58.3 \pm 26.2$ & $56.6 \pm 32.1$ & 0.602 \\
\hline
\end{tabular}

${ }^{*}$ Kruskall-Wallis test.

with the General Health of PGWB $(P=0.031)$.

The prevalence of cases exceeding the selected cut-offs is reported in Table 3. Significant differences were only observed in the Somatization scale of SCL-90, but in most cases the data showed a Jshaped curve, with participants with normal BMI20 or those with Class II-III obesity in early adulthood having the highest prevalence of psychological/psychiatric distress and poor HRQL at ORWELL-97.

Step-wise logistic regression analysis identified either diet history (cumulative BMI loss) or somatic score as factors significantly associated with psychological/psychiatric distress and poor HRQL (Table 4). In particular, weight cycling was significantly associated with binge eating, depression, interpersonal sensitivity and HRQL, whereas the somatic score was the leading cause of poor performance in several scales of SCL-90 and all scales of PGWB. BMI-20 was not associated with any of the various domains tested in data adjusted for age, gender and BMI.

\section{Discussion}

To our knowledge, this is the first study to address the relation between age at onset of obesity and psychological profile in morbid obesity. The underlying hypothesis was that subjects who are obese before the age of 20 years might undergo an adaptation process, which allows them to cope better with the psychological distress linked to the stigma of obesity. This hypothesis was not fully verified in the large QUOVADIS database. Small differences in the Somatization scale of SCL-90 were demonstrated, but they were entirely cancelled out after correction 
Table 3. Prevalence (\%) of scores of the Binge Eating Scale, Symptom CheckList-90 and ORWELL 97 above the selected cut-offs, according to BMI at the age 20 years (mean \pm SD)

\begin{tabular}{|c|c|c|c|c|c|}
\hline & $\begin{array}{c}\text { BMI-20, }<25 \\
(\mathrm{n}=221)\end{array}$ & $\begin{array}{c}\text { BMI-20, 25-30 } \\
\quad(n=198)\end{array}$ & $\begin{array}{c}\text { BMI-20, 30-35 } \\
(n=126)\end{array}$ & $\begin{array}{l}\text { BMI-20, >35 } \\
\quad(n=87)\end{array}$ & $P^{\star}$ \\
\hline \multicolumn{6}{|l|}{ Binge Eating Scale } \\
\hline Score $17-26$ & 29.2 & 21.9 & 34.7 & 28.7 & 0.162 \\
\hline Score $\geq 27$ & 14.6 & 17.7 & 11.3 & 18.4 & 0.629 \\
\hline \multicolumn{6}{|c|}{ Symptom CheckList-90 (scores >1.0) } \\
\hline General Symptom Index & 38.8 & 33.5 & 33.9 & 38.8 & 0.612 \\
\hline Somatization & 64.4 & 51.8 & 55.6 & 50.6 & 0.036 \\
\hline Obsessive-compulsive thoughts & 42.9 & 38.1 & 36.3 & 41.2 & 0.606 \\
\hline Interpersonal sensitivity & 41.6 & 42.6 & 43.6 & 45.9 & 0.920 \\
\hline Depression & 47.0 & 41.1 & 46.0 & 41.2 & 0.584 \\
\hline Anxiety & 39.7 & 35.0 & 33.9 & 36.5 & 0.676 \\
\hline Hostility & 30.6 & 29.4 & 33.9 & 35.3 & 0.717 \\
\hline Phobic anxiety & 18.3 & 17.8 & 9.7 & 20.0 & 0.659 \\
\hline Paranoid conceiving & 42.5 & 41.6 & 48.4 & 42.4 & 0.656 \\
\hline Psychotic behavior & 15.5 & 20.8 & 15.3 & 21.2 & 0.370 \\
\hline \multicolumn{6}{|c|}{ Psychological General Well-Being (Z-score $\leq 1.0)$} \\
\hline Total score & 40.7 & 37.1 & 36.0 & 42.5 & 0.679 \\
\hline Depressed mood & 29.0 & 24.8 & 27.2 & 34.5 & 0.414 \\
\hline Anxiety & 33.0 & 27.9 & 22.4 & 33.3 & 0.149 \\
\hline Positive well-being & 34.9 & 32.5 & 29.6 & 40.2 & 0.431 \\
\hline Self-control & 37.1 & 30.5 & 31.2 & 35.6 & 0.463 \\
\hline General health & 43.4 & 39.1 & 42.4 & 42.5 & 0.832 \\
\hline Vitality & 36.7 & 41.1 & 34.4 & 36.8 & 0.639 \\
\hline ORWELL-97 & 37.3 & 35.4 & 33.9 & 35.6 & 0.935 \\
\hline
\end{tabular}

${ }^{*}$ Kruskall-Wallis test.

for age. Age at onset of obesity did not appear to influence any of the subscales of SCL-90, with the only exception of the Somatization scale, which was significantly more impaired in those with normal weight at early adulthood. According to Rosik, ${ }^{18}$ an Axis I disorder is present in about half of morbidly obese candidates for bariatric surgery treatment, and somatization represents the most common aspect of psychiatric distress in this cohort. However, the higher Somatization score in the subjects with normal weight at age 20 years is largely dependent on the more prolonged obesity history and associated somatic burden. In the Swedish Obese Subjects study, where the age at onset of obesity was on average 20 years, the participants had evidence of severe obesity-related distress and reported poor coping strategies. ${ }^{19}$ We conclude that early-onset obesity per se is neither a protective nor a worsening factor for major psychiatric co-morbidity.

General Health at PGWB remains the sole scale independently associated with early-onset obesity. The General Health domain reflects the global perceived health status in the last 4 weeks, the possibility to carry out everyday activities and the concern for present health. It is the domain more closely associated with somatic diseases. ${ }^{13}$ A history of higher-than-normal BMI at age 20 years was associated with a better score, independently of age differences. Although the prevalence of subjects with a pathological score was not different in relation to BMI-20, these data may support our initial hypothesis that subjects living with morbid obesity since their childhood may partly adapt to the distress generated by their disease. 
Table 4. Step-wise logistic regression analysis of factors predicting psychiatric/psychological distress in Class III obese participants (odds ratio and $95 \%$ confidence intervals). All data are adjusted for age, gender and BMI

\begin{tabular}{|c|c|c|c|c|}
\hline Dependent variables & Independent variables & OR & $95 \% \mathrm{Cl}$ & $P^{*}$ \\
\hline \multicolumn{5}{|l|}{ Binge Eating Scale } \\
\hline Score $17-26$ & Cumulative BMI loss & 1.80 & $1.18-2.75$ & 0.006 \\
\hline Score $\geq 27$ & Cumulative BMI loss & 2.33 & $1.40-3.89$ & 0.001 \\
\hline \multicolumn{5}{|c|}{ Symptom CheckList-90 (scores >1.0) } \\
\hline General Index & Somatic score & 1.26 & $1.08-1.47$ & 0.003 \\
\hline Somatization & Somatic score & 1.34 & $1.14-1.56$ & $<0.001$ \\
\hline Obsessive-compulsive thoughts & Somatic score & 1.31 & $1.10-1.57$ & 0.003 \\
\hline Interpersonal sensitivity & Cumulative BMI loss & 1.64 & $1.07-2.51$ & 0.022 \\
\hline Depression & Cumulative BMI loss & 1.51 & $1.00-2.29$ & 0.050 \\
\hline Anxiety & Somatic score & 1.25 & $1.03-1.51$ & 0.021 \\
\hline Hostility & Somatic score & 1.44 & $1.17-1.76$ & $<0.001$ \\
\hline Phobic anxiety & Somatic score & 1.50 & $1.16-1.96$ & 0.002 \\
\hline Paranoid conceiving & ------------- & ---- & ---------- & ----- \\
\hline Psychotic behavior & ------------- & ---- & --------- & ----- \\
\hline \multicolumn{5}{|c|}{ Psychological General Well-Being (Z-score $\leq 1.0$ ) } \\
\hline Total score & Somatic score & 1.38 & $1.18-1.60$ & $<0.001$ \\
\hline Depressed mood & Somatic score & 1.25 & $1.06-1.47$ & 0.006 \\
\hline Anxiety & Somatic score & 1.28 & $1.09-1.51$ & 0.002 \\
\hline Positive well-being & Somatic score & 1.31 & $1.12-1.52$ & $<0.001$ \\
\hline Self-control & Somatic score & 1.22 & $1.05-1.42$ & 0.010 \\
\hline General health & Somatic score & 1.52 & $1.30-1.78$ & $<0.001$ \\
\hline Vitality & Somatic score & 1.35 & $1.16-1.57$ & $<0.001$ \\
\hline ORWELL-97 & Recurrent dieting & 1.69 & $1.13-2.54$ & 0.011 \\
\hline
\end{tabular}

*Kruskall-Wallis test.

The major determinants of psychological/psychiatric distress in our series were largely expected, on the basis of the association of weight cycling with psychological symptoms ${ }^{20}$ and the effects of both psychiatric distress $^{21}$ and somatic diseases on perceived health status in obesity. ${ }^{22}$ In keeping with our data, the large Swedish experience pointed out that psychosocial functioning of morbidly obese subjects is significantly related to the number of previous dieting attempts. ${ }^{23}$ There is also a wide consensus about the association between weight cycling and binge eating. ${ }^{5,24,25}$ On the contrary, an association between weight cycling and depression in obesity in general has been reported in a few cohorts, ${ }^{20,26,27}$ but denied in other settings. ${ }^{28,29}$ There is no unequivocal definition for weight cycling. In a recent paper, we defined a few surrogate markers for weight cycling, ${ }^{5}$ including cumulative BMI loss. According to this definition, weight cycling appears to be a risk factor for a pathological Depression scale of SCL-90, at least in this cohort of morbidly obese participants.

Also increased interpersonal sensitivity represents a core psychological feature of morbid obesity. It was defined as an "undue and excessive awareness of, and sensitivity to, the behavior and feelings of others". ${ }^{30}$ Our study gives evidence to weight cycling as a key component of interpersonal oversensitivity, which is known to be favorably affected by weight loss following bariatric surgery. ${ }^{31}$

Finally, binge eating was associated with weight cycling, as repeatedly demonstrated in various obese cohorts, ${ }^{32,33}$ including the general QUOVADIS database, ${ }^{5}$ but this specific psychopathological feature was not different in relation to early $v s$ late-onset morbid obesity. 
The most relevant finding of the present study is that obesity-related somatic diseases, evaluated by the modified Charlson score, ${ }^{17}$ mainly account for psychological distress measured by the various domains of PGWB and for most impaired domains of SCL-90. Somatic diseases were the leading risk factor of poor performance also for scales, such as Anxiety, Hostility and anger or Obsessive-compulsive thoughts, which are expected to be primarily associated with mental health more than somatic health. Unexpectedly, their HRQL, measured by the obesity-specific instrument ORWELL-97, was not influenced by the score of somatic diseases. The ORWELL-97 considers both the occurrence and the severity of obesity-related symptoms and their subjective importance in everyday life, ${ }^{16}$ but only the occurrence of symptoms is related to BMI. The ORWELL-97 was not specifically developed for morbid obesity. The relatively unsatisfactory performance of this instrument in our hands might reflect a general difficulty in measuring HRQL in these highly-complicated patients, or the high heterogeneity of this subpopulation. A large number of questionnaires have been developed or adapted for use in morbid obesity, and new ones add to the list every year, thus indirectly confirming how far we are from an exact definition of what specifically impairs quality of life in a morbidly obese person. ${ }^{34}$ Again, weight cycling may have a definite role, as expressed by the association with recurrent dieting.

In conclusion, this study suggests that the psychological/psychiatric traits of morbidly obese subjects are scarcely influenced by the age of onset of obesity. The possibility that early-onset obesity might either produce a systematic adaptation or further increase psychiatric distress due to long-term stigma is largely ruled out by the QUOVADIS data. Physicians in charge of these treatment-seeking patients must be aware of the large heterogeneity of these patients' psychological traits and perceived health status, ${ }^{10,35,36}$ and of the importance of the burden of somatic disease and weight cycling as factors negatively influencing their mental distress and HRQL.

The QUOVADIS Study is supported by an unrestricted grant from BRACCO Imaging Spa, Milan.

\section{References}

1. Dalle Grave R, Calugi S, Molinari E et al. Weight loss expectations in obese patients and treatment attrition: an observational multicenter study. Obes Res 2005; 13: 1961-9.

2. Marchesini G, Melchionda N, Apolone G et al. The metabolic syndrome in treatment-seeking obese persons. Metabolism 2004; 53: 435-40.

3. Melchionda N, Marchesini G, Apolone G et al. The QUOVADIS study. Features of obese Italian patients seeking treatment at specialist centers. Diabetes Nutr Metab 2003; 16: 115-24.

4. Kuehnel RH, Wadden TA. Binge eating disorder, weight cycling, and psychopathology. Int J Eat Disord 1994; 15: 321-9.

5. Marchesini G, Cuzzolaro M, Mannucci E et al. Weight cycling in treatment-seeking obese persons: data from the QUOVADIS study. Int J Obes 2004; 28 : 1456-62.

6. Fontaine KR, Barofsky I, Cheskin LJ. Predictors of quality of life for obese persons. J Nerv Ment Dis 1997; 185: 120-2.

7. Fontaine KR, Bartlett SJ, Barofsky I. Health-related quality of life among obese persons seeking and not currently seeking treatment. Int J Eat Disord 2000; 27: 101-5.

8. Sendi P, Brunotte R, Potoczna N et al. Health-related quality of life in patients with class II and class III obesity. Obes Surg 2005; 15: 1070-6.

9. Fabricatore AN, Wadden TA, Sarwer DB et al. Health-related quality of life and symptoms of depression in extremely obese persons seeking bariatric surgery. Obes Surg 2005; 15: 304-9.

10. van Hout GC, van Oudheusden I, van Heck GL. Psychological profile of the morbidly obese. Obes Surg 2004; 14: 579-88.

11.Derogatis LR, Rickels K, Rock AF. The SCL-90 and the MMPI: a step in the validation of a new self-report scale. Br J Psychiatry 1976; 128: 280-9.

12. Derogatis LR, Cleary PA. Confirmation of the dimensional structure of the SCL-90: a study in construct validity. J Clin Psychol 1977; 33: 981-9.

13. Dupuy HJ. The psychological general well-being (PGWB) inventory. In: Wenger NK, ed. Assessment of Quality of Life in Clinical Trials of Cardiovascular Therapies. New York: Le Jacq Publications 1984: 170-83.

14. Grossi E, Mosconi P, Groth N et al. Il Questionario Psychological General Well-Being. Versione Italiana. Edizioni "Mario Negri", 2002.

15. Gormally J, Block S, Daston S et al. The assessment 
of binge eating severity among obese persons. Addict Behav 1982; 7: 47-55.

16. Mannucci E, Ricca V, Barciulli E et al. Quality of life and overweight: the obesity related well-being (Orwell 97) questionnaire. Addict Behav 1999; 24: 345-57.

17. Charlson ME, Pompei P, Ales KL et al. A new method of classifying prognostic comorbidity in longitudinal studies: development and validation. J Chronic Dis 1987; 40: 373-83.

18. Rosik CH. Psychiatric symptoms among prospective bariatric surgery patients: rates of prevalence and their relation to social desirability, pursuit of surgery, and follow-up attendance. Obes Surg 2005; 15: 677-83.

19. Ryden A, Karlsson J, Persson LO et al. Obesity-related coping and distress and relationship to treatment preference. Br J Clin Psychol 2001; 40: 177-88.

20. Kensinger GJ, Murtaugh MA, Reichmann SK et al. Psychological symptoms are greater among weight cycling women with severe binge eating behavior. J Am Diet Assoc 1998; 98: 863-8.

21. Marchesini G, Bellini M, Natale S et al. Psychiatric distress and health-related quality of life in obesity. Diab Nutr Metab 2003; 16: 145-54.

22. Marchesini G, Natale S, Tiraferri F et al. The burden of obesity on everyday life: a role for osteoarticular and respiratory diseases. Diabetes Nutr Metab 2003; 16: 284-90.

23. Sullivan M, Karlsson J, Sjöström L et al. Swedish obese subjects (SOS) - an intervention study of obesity. Baseline evaluation and psychosocial functioning in the first 1743 subjects examined. Int J Obes 1993; 17: 503-12.

24. National Task Force on the Prevention and Treatment of Obesity. Overweight, obesity, and health risk. Arch Intern Med 2000; 160: 898-904.

25. Elfhag K, Rossner S. Who succeeds in maintaining weight loss? A conceptual review of factors associated with weight loss maintenance and weight regain.
Obes Rev 2005; 6: 67-85.

26. Womble LG, Williamson DA, Martin CK et al. Psychosocial variables associated with binge eating in obese males and females. Int J Eat Disord 2001; 30: 217-21.

27. Walfish S. Self-assessed emotional factors contributing to increased weight gain in pre-surgical bariatric patients. Obes Surg 2004; 14: 1402-5.

28. Simkin-Silverman LR, Wing RR, Plantinga $P$ et al. Lifetime weight cycling and psychological health in normal-weight and overweight women. Int $\mathrm{J}$ Eat Disord 1998; 24: 175-83.

29. Foster GD, Wadden TA, Kendall PC et al. Psychological effects of weight loss and regain: a prospective evaluation. J Consult Clin Psychol 1996; 64: 752-7.

30. Boyce P, Parker G. Development of a scale to measure interpersonal sensitivity. Aust N Z J Psychiatry 1989; 23: 341-51.

31. Mamplekou E, Komesidou V, Bissias C et al. Psychological condition and quality of life in patients with morbid obesity before and after surgical weight loss. Obes Surg 2005; 15: 1177-84.

32. Yanovski SZ, Sebring NG. Recorded food intake of obese women with binge eating disorder before and after weight loss. Int J Eat Disord 1994; 15: 135-50.

33. Venditti EM, Wing RR, Jakicic JM et al. Weight cycling, psychological health, and binge eating in obese women. J Consult Clin Psychol 1996; 64: 400-5.

34. Wadden TA, Phelan S. Assessment of quality of life in obese individuals. Obes Res 2002; 10 (Suppl 1): 50S-57S.

35. Van Hout GC, Van Oudheusden I, Krasuska AT et al. Psychological profile of candidates for vertical banded gastroplasty. Obes Surg 2006; 16: 67-74.

36. Duval K, Marceau P, Lescelleur O et al. Health-related quality of life in morbid obesity. Obes Surg 2006; 16: 574-9.

(Received August 17, 2006; accepted September 29, 2006) 